\title{
Neal Oxenhandler, Rimbaud. The Cost of Genius
}

\section{Maria Emanuela Raffi}

\section{OpenEdition}

\section{Journals}

\section{Edizione digitale}

URL: http://journals.openedition.org/studifrancesi/5719

DOI: 10.4000/studifrancesi.5719

ISSN: 2421-5856

\section{Editore}

Rosenberg \& Sellier

\section{Edizione cartacea}

Data di pubblicazione: 1 septembre 2011

Paginazione: 445

ISSN: 0039-2944

\section{Notizia bibliografica digitale}

Maria Emanuela Raffi, «Neal Oxenhandler, Rimbaud. The Cost of Genius», Studi Francesi [Online], 164 (LV

| II) | 2011, online dal 30 novembre 2015, consultato il 12 janvier 2021. URL: http://

journals.openedition.org/studifrancesi/5719 ; DOI: https://doi.org/10.4000/studifrancesi.5719

Questo documento è stato generato automaticamente il 12 janvier 2021.

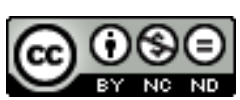

Studi Francesi è distribuita con Licenza Creative Commons Attribuzione - Non commerciale - Non opere derivate 4.0 Internazionale. 


\title{
Neal Oxenhandler, Rimbaud. The Cost of Genius
}

\author{
Maria Emanuela Raffi
}

\section{NOTIZIA}

NEAL OXENHANDLER, Rimbaud. The Cost of Genius, Ohio State University, 2009, 169 pp.

La lettura di Rimbaud proposta da Neal OXENHANDLER s'iscrive nella più generale prospettiva della psicocritica, che prende avvio, secondo l'A., dal saggio di C.A. Hackett, Rimbaud l'enfant del 1948. Intreccio privilegiato di temi psicoanalitici, i testi poetici rimbaudiani formulati spesso come veri e propri enigmi, sembrano infatti illustrare perfettamente la formula di Barthes «figure di desiderio», dove psiche e testo si intrecciano. È il gioco del transfert e del contro-transfert nel dialogo con i lettori, attraverso le immagini fuggitive dei testi, che motiva per OXENHANDLER la grandezza di Rimbaud nella storia letteraria. La psicoanalisi ha consentito, secondo l'A., la formulazione di un nuovo linguaggio per dire l'intreccio fra corpo e anima, ma l'applicazione di tale linguaggio all'opera di Rimbaud ha posto delle difficoltà. In particolare, la domanda fondamentale che il saggio propone riguarda il prezzo pagato da Rimbaud per realizzare la sua opera e la risposta non appare semplice, poiché ogni poesia è fondata su una specifica situazione e per ognuna l'autore ha pagato un prezzo personale. Una larga parte di questo prezzo consiste nell'uso della sua persona attraverso la poetica della voyance, intesa come disciplina ascetica, che include elementi come la repressione e l'autopunizione e lavora come una visione ontologica per tutta la vita di Rimbaud. Un altro prezzo importante pagato dal poeta di Charleville è per Oxenhandler il modo in cui l'arte gli ha sottratto la vita, dinamica particolarmente visibile nell'ultima parte di «Angoisse».

2 Dopo aver tracciato il percorso degli studi su Rimbaud che hanno in qualche modo seguito dei principi psicoanalitici, da Hackett a Bonnefoy, Leo Bersani, Michel Collot, Sergio Sacchi e Jean-Luc Steinmetz, oxenhandler conclude il capitolo introduttivo 
sottolineando come lo studio di alcune figure dei testi rimbaudiani («psychic tropes») consenta di arrivare ai procedimenti psichici che hanno dato origine ai testi poetici.

3 A partire da queste premesse teoriche, l'A. analizza una serie di testi di Rimbaud organizzati in capitoletti successivi: «Le poète de sept ans», «Le Bateau ivre», «Mémoire», «Le Cœur du pitre», "A Une Raison», «Démocratie», «Après le déluge», «Honte», «Angoisse», «Aube», «Vies I, II, III», «H», «Conte», «Nocturne vulgaire», «Génie», «Solde», «Villes II». L'ultimo capitolo è interamente dedicato alla «Sublimation in Une Saison en enfer». 